\title{
Can Dehydroepiandrostenedione (DHEA) target PRL-3 to prevent colon cancer metastasis?
}

\author{
Jyotsna Sundar and Munirathinam Gnanasekar*
}

Department of Biomedical Sciences, University of Illinois, College of Medicine, Rockford, IL 61107, USA

Key words: DHEA, PRL-3 and colon cancer

\section{Running title:}

*Corresponding author, Department of Biomedical Sciences, University of Illinois, College of Medicine, 1601 Parkview Ave, Rockford, IL 61107. Phone: 815-395-5773; Fax: 815-395-5666. email:mgnanas@uic.edu 


\section{Abstract:}

Colorectal cancer (CRC) is a frequently diagnosed cancer and causing significant mortality in the patients. Metastasis caused by CRC is mainly responsible for this cancer-related deaths. Despite recent advancements in the treatment methods, prognosis remains poor. Therefore, effective treatment strategies need to be designed for successful management of this disease.

Dehydroepiandrostenedione (DHEA), a 17-ketosteroid hormone produced by adrenal glands, gonads and including gastrointestinal tract is required for several physiological processes.

Deregulation of DHEA levels leads to various disease conditions including cancer. In fact, several experimental studies strongly suggest that DHEA could be used as a chemopreventive agent against colon cancer. Prenlyation of certain membrane proteins such as phosphatase of regenerating liver-3 (PRL-3) is crucial for metastatic progression of colon cancer cells. The ability of DHEA to target prenylation pathway could be utilized to inhibit PRL-3 prenylation for successful prevention of CRC metastases. As DHEA is a widely consumed drug for various ailments, incorporation of DHEA in the treatment regimen may be beneficial to prevent or delay the occurrence of metastasis resulting from CRC. 


\section{Introduction/Background:}

Colorectal cancer (CRC) is the third most common cancer in the United States and is second only to lung cancer as a cause of cancer-related mortality. Occult metastasis is a frequent issue encountered in CRC. The liver is the most common and often the only site of metastatic disease. The presence of colorectal liver metastases (CLM) is associated with a poor prognosis, with a median survival ranging between six and twelve months. However, what causes metastases in CRC patients remains poorly understood. CRC treatment depends on the grade and the stage of the tumor diagnosed in patients. Stage 1 tumors are associated with a good prognosis. Surgical intervention followed by chemotherapy is the standard treatment module currently employed with an outcome of five year survival rate ranging between $25 \%$ and $58 \%$ [1].

Despite recent advances in diagnostic and therapeutic measures, the prognosis of CRC remains poor and the treatments are associated with serious morbidity and mortality. Hence there is a need to develop alternative effective and non-toxic treatment strategies for successful management of CRC. The identification of biomarkers which might capture tumor properties not reflected by clinicopathological variables has become essential to improve prognosis and will aid clinicians to efficiently manage the disease [2]. Colonic carcinogenesis is characterized by the accumulation of proto-oncogene and tumor suppressor gene mutations. Consistent genetic alterations associated with the transition from primary colorectal cancers to liver metastases was studied by Saha et al [3] who performed the serial analysis of gene expression profiles. This lead to the identification of PRL-3 (phosphatase of regenerating liver-3/PTP4A3) which was found to be frequently overexpressed in the liver metastases, but expressed at lower levels in primary 
tumors and normal colorectal epithelium [3]. Subsequent studies have re-affirmed that PRL-3 is a metastasis related protein and a promising therapeutic target for cancer metastasis $[4,5]$.

PRL-3 belongs to the PRL class of proteins which constitutes (PRL-1, PRL-2 \& PRL-3) and they share at least $75 \%$ amino acid sequence similarity [6]. Of all PRLs, PRL-3 plays a major role in cancer metastasis [7]. PRL-3 has two functional domains, the catalytic domain functions as a protein tyrosine phosphatase (PTP) for dephosphorylation (Figure 1). The specific substrate for PRL-3 in vivo has not been clearly identified, although it has been addressed in prior studies about the importance of the PTP domain in promoting cancer cell growth, invasion and metastasis [8], The other functional domain of PRL-3 is the CCVM motif for prenylation. Isoprenylation is a common post-translational modification for proteins that are targeted to membranes. The CAAX sequence on the C-terminal of PRL-3 constitutes a conserved feature of this type of protein family.

Metastatic functions of PRL-3 depends on its association with the inner surface of the plasma membrane [5]. It is initially synthesized as a soluble protein lacking the hydrophobic domain and then they are posttranslationally modified with prenylation for its membrane localization. The prenylation motifs such as CAAX, XXCC, XCXC and CCXX are recognized by farnesyltransferase (FT) or geranylgeranyltransferase (GGT) which aid in the correct localization of target proteins. The CAAX prenylation motif present in the c-terminal region of PRL-3 protein (Figure 1) has shown to be important for membrane interaction of PRL3 thereby enabling their participation in various signal transduction pathways [5]. Mutation of the prenylation site or inhibition of prenylation substrate synthesis blocks prenylation and thus membrane localization, resulting in loss of normal protein function [9]. Interestingly, disruption of PRL-3 prenylation by mutation studies has shown to eliminate the metastatic potential of 
melanoma cells [5]. However to our knowledge there are no studies conducted to date to show prenylation inhibitors could be used to target PRL-3 to manage cancer metastases.

Prior studies have shown that Dehydroepiandrostenedione (DHEA) is a prenylation inhibitor [10] and can confer protection against colorectal cancer [11]. DHEA is a 17ketosteroid (Figure 2) produced at high levels in the adrenal gland, gastrointestinal tract, gonads, and brain [12]. It is the chief precursor of androstenedione, which gets readily converted into testosterone and $17 \beta$-estradiol in the tissues. Being the most abundant steroid in human circulation, it serves multiple functions in maintaining the physiological homeostasis. Previous studies on animal model systems revealed that DHEA is a powerful inhibitor of mammary, prostate, skin, lung, liver, and thyroid carcinogenesis [13-18]. DHEA has been associated with various beneficial effects such as anti obesity [19], lowering of blood glucose [20], and antiatherosclerosis [21]. DHEA is also known to be effective in improving the negative, depressive and anxiety symptoms in Schizophrenia patients with no obvious adverse effects reported in the study participants [22]. In another study, DHEA is shown to be useful in enhancing the psychological well-being in male and female hypopituitary patients on maintenance growth hormone replacement [23]. However, few side effects such as greasy skin, diarrhea and muscle aches were reported in some patients of this study depending on the gender [23]. Strikingly, low DHEA levels are associated with increased risks of tumorigenesis as studies show that administration of DHEA prevents spontaneous tumorigenesis in p53-nullizygous mice [24]. However the mechanism of how DHEA decreases carcinogenesis is unclear and may be multifactorial. Previously, Schulz and Nyce [10] found that DHEA can inhibit cholesterol biosynthesis and inhibit posttranslational processing events such as isoprenylation of membrane associated oncogenic p21ras protein in colon adenocarcinoma cells. Therefore, it is possible that 
DHEA might target posttranslational processing of PRL-3 protein thereby causing an inhibition of its metastatic function in CRC. 


\section{THE HYPOTHESIS:}

Dehydroepiandrostenedione (DHEA), an adrenal steroid, has been shown to inhibit early steps of prenylation pathway [10]. Isoprenylation is a necessary prerequisite for membrane association of key oncogenic proteins such as PRL-3, RhoA and Ras [25-27]. Therefore, we hypothesize that DHEA can prevent the isoprenylation of PRL-3 protein leading to the disruption of its function in colon carcinoma metastasis.

\section{EVALUATION OF HYPOTHESIS:}

\section{The structure of PRL-3 protein:}

As PRL-3 belongs to the PTP superfamily, they have an N-terminal catalytic domain containing the signature motif $\mathrm{CX}_{5} \mathrm{R}$ (Figure 1). The C-terminal domain of the PRLs contains a polybasic region which immediately precedes a CAAX box, where the $\mathrm{C}$ is cysteine, $\mathrm{A}$ is an aliphatic residue and $\mathrm{X}$ is any amino acid. This box represents the prenylation motif, which is unique only for the PRL-PTP family [28]. The association of the PRLs with the plasma membrane and early endosome in the cells is attributed to this prenylation motif which is subjected to farnesylation, a post-translational lipid modification known as resulting in the membrane localization of protein. The polybasic region may also serve as a nuclear localization signal to direct PRLs to the nucleus in the absence of prenylation [9].

Prenylation of PRL-3 was found to be important for metastatic properties of cancer cells [29].The localization of PRL-3 to the plasma membrane is a critical requirement for its function. Isoprenylation is the first step in a series of posttranslational processing events promoting the stable association of PRL-3 protein with the cell membrane and will further enable the celltransforming activity of oncogenic PRL-3 protein. 


\section{DHEA and PRL-3:}

De novo cholesterol synthesis pathway is of vital importance for providing substrates for protein prenylation. It has been reported that DHEA treatment can inhibit cholesterol biosynthesis in lactating mammary gland [30]. The first and rate-limiting step in this pathway is catalyzed by HMG-CoA reductase. Previous studies show that DHEA inhibits p21ras prenylation in colon adenocarcinoma cells [10]. It functions as a HMG-CoA reductase inhibitor (Figure 3), in a manner similar to Lovostatin [10]. Inhibition of this enzyme leads to the depletion of mevalonate and further inhibits the prenylation of p21ras. Therefore, this drug could be used as a promising chemopreventive agent. In fact, several experimental studies suggest DHEA to be a promising anti-cancer agent $[13,31-33]$. In addition, DHEA is also shown to inhibit migration and invasion properties of metastatic cancer cells [34]. However, it is not clear how DHEA targets metastatic properties of cancer cells. Since DHEA is shown to be a prenylation inhibitor, we hypothesize that consumption of DHEA will prevent colon cancer metastases by targeting the prenylation of PRL-3. This hypothesis can be tested using in vitro and in vivo model of colon cancer metastases. If DHEA shows promise in pre-clinical studies, then these results can be easily translatable in colon cancer patients as DHEA is an approved drug used for various health benefits.

\section{Implications of the hypothesis:}

DHEA is the most abundant adrenal steroid with apparent anticarcinogenic properties. Our hypothetical study suggests that DHEA could potentially inhibit isoprenylation of PRL-3 protein, involved in colon cancer metastasis, at a point in the protein prenylation pathway distal to HMGCoA reductase activity. Our predictions might provide a plausible explanation for the antitumor action of DHEA on PRL-3 mediated metastasis in colon carcinoma. Hence, the use of DHEA as 
an inhibitor of isoprenylation will represent a rational, targeted approach for the development of DHEA as a mechanism-based chemopreventive drug for CRC.

\section{Conflict of Interest Statement:}

The authors have no conflict of interest to declare.

\section{Acknowledgment}

Study partly supported by University of Illinois Rockford Health Sciences Innovation in Education, Research and Community Project. 
References:

1. Slesser AA, Georgiou P, Brown G, Mudan S, Goldin R, Tekkis P: The tumour biology of synchronous and metachronous colorectal liver metastases: a systematic review. Clin Exp Metastasis.

2. Tai CJ, Lee CH, Chen HC, Wang HK, Jiang MC, Su TC, Shen KH, Lin SH, Yeh CM, Chen CJ et al: High nuclear expression of phosphorylated extracellular signal-regulated kinase in tumor cells in colorectal glands is associated with poor outcome in colorectal cancer. Ann Diagn Pathol.

3. Saha S, Bardelli A, Buckhaults P, Velculescu VE, Rago C, St Croix B, Romans KE, Choti MA, Lengauer $C$, Kinzler KW et al: A phosphatase associated with metastasis of colorectal cancer. Science 2001, 294(5545):1343-1346.

4. Matsukawa Y, Semba S, Kato H, Koma Y, Yanagihara K, Yokozaki H: Constitutive suppression of PRL-3 inhibits invasion and proliferation of gastric cancer cell in vitro and in vivo. Pathobiology, 77(3):155-162.

5. Song R, Qian F, Li YP, Sheng X, Cao SX, Xu Q: Phosphatase of regenerating liver-3 localizes to cyto-membrane and is required for B16F1 melanoma cell metastasis in vitro and in vivo. PLOS One 2009, 4(2):e4450.

6. Kozlov G, Cheng J, Ziomek E, Banville D, Gehring K, Ekiel I: Structural insights into molecular function of the metastasis-associated phosphatase PRL-3. J Biol Chem 2004, 279(12):1188211889 .

7. Al-Aidaroos AQ, Zeng Q: PRL-3 phosphatase and cancer metastasis. J Cell Biochem, 111(5):10871098.

8. M iskad UA, Semba S, Kato H, Yokozaki H: Expression of PRL-3 phosphatase in human gastric carcinomas: close correlation with invasion and metastasis. Pathobiology 2004, 71(4):176-184.

9. Zeng Q, Si X, Horstmann H, Xu Y, Hong W, Pallen C): Prenylation-dependent association of protein-tyrosine phosphatases PRL-1, -2 , and -3 with the plasma membrane and the early endosome. J Biol Chem 2000, 275(28):21444-21452.

10. Schulz S, Nyce JW: Inhibition of protein isoprenylation and p21ras membrane association by dehydroepiandrosterone in human colonic adenocarcinoma cells in vitro. Cancer Res 1991, 51(24):6563-6567.

11. Klann RC, Holbrook CT, Nyce JW: Chemotherapy of murine colorectal carcinoma with cisplatin and cisplatin plus 3'-deoxy-3'-azidothymidine. Anticancer Res 1992, 12(3):781-787.

12. Parker CR, Jr.: Dehydroepiandrosterone and dehydroepiandrosterone sulfate production in the human adrenal during development and aging. Steroids 1999, 64(9):640-647.

13. Shilkaitis A, Green A, Punj V, Steele V, Lubet R, Christov K: Dehydroepiandrosterone inhibits the progression phase of mammary carcinogenesis by inducing cellular senescence via a p16dependent but p53-independent mechanism. Breast Cancer Res 2005, 7(6):R1132-1140.

14. Rao KV, Johnson WD, Bosland M C, Lubet RA, Steele VE, Kelloff GJ, M cCormick DL: Chemoprevention of rat prostate carcinogenesis by early and delayed administration of dehydroepiandrosterone. Cancer Res 1999, 59(13):3084-3089.

15. Pashko LL, Lewbart M L, Schwartz AG: Inhibition of 12-0-tetradecanoylphorbol-13-acetatepromoted skin tumor formation in mice by 16 alpha-fluoro-5-androsten-17-one and its reversal by deoxyribonucleosides. Carcinogenesis 1991, 12(11):2189-2192.

16. Schwartz AG, Pashko L, Whitcomb JM : Inhibition of tumor development by dehydroepiandrosterone and related steroids. Toxicol Pathol 1986, 14(3):357-362.

17. Simile M, Pascale RM, De Miglio M R, Nufris A, Daino L, Seddaiu M A, Muroni M R, Rao KN, Feo F: Inhibition by dehydroepiandrosterone of growth and progression of persistent liver nodules in experimental rat liver carcinogenesis. Int J Cancer 1995, 62(2):210-215. 
18. Moore MA, Thamavit W, Tsuda H, Sato K, Ichihara A, Ito N: Modifying influence of dehydroepiandrosterone on the development of dihydroxy-di-n-propylnitrosamine-initiated lesions in the thyroid, lung and liver of F344 rats. Carcinogenesis 1986, 7(2):311-316.

19. Schwartz AG, Hard GC, Pashko LL, Abou-Gharbia M, Swern D: Dehydroepiandrosterone: an antiobesity and anti-carcinogenic agent. Nutr Cancer 1981, 3(1):46-53.

20. Aoki K, Taniguchi H, Ito Y, Satoh S, Nakamura S, Muramatsu K, Yamashita R, Ito S, M ori Y, Sekihara $\mathrm{H}$ : Dehydroepiandrosterone decreases elevated hepatic glucose production in C57BL/ KsJ-db/ db mice. Life Sci 2004, 74(25):3075-3084.

21. Hayashi T, Esaki T, M uto E, Kano H, Asai Y, Thakur NK, Sumi D, Jayachandran M, Iguchi A: Dehydroepiandrosterone retards atherosclerosis formation through its conversion to estrogen: the possible role of nitric oxide. Arterioscler Thromb Vasc Biol 2000, 20(3):782-792.

22. Strous RD, Maayan R, Lapidus R, Stryjer R, Lustig M, Kotler M, Weizman A:

Dehydroepiandrosterone augmentation in the management of negative, depressive, and anxiety symptoms in schizophrenia. Arch Gen Psychiatry 2003, 60(2):133-141.

23. Brooke AM, Kalingag LA, M iraki-M oud F, Camacho-Hubner C, Maher KT, Walker DM, Hinson JP, Monson JP: Dehydroepiandrosterone improves psychological well-being in male and female hypopituitary patients on maintenance growth hormone replacement. J Clin Endocrinol M etab 2006, 91(10):3773-3779.

24. Hursting SD, Perkins SN, Haines DC, Ward JM, Phang JM : Chemoprevention of spontaneous tumorigenesis in p53-knockout mice. Cancer Res 1995, 55(18):3949-3953.

25. Li T, Sparano JA: Inhibiting Ras signaling in the therapy of breast cancer. Clin Breast Cancer 2003, 3(6):405-416; discussion 417-420.

26. Collisson EA, Carranza DC, Chen IY, Kolodney MS: Isoprenylation is necessary for the full invasive potential of RhoA overexpression in human melanoma cells. J Invest Dermatol 2002, 119(5):1172-1176.

27. Bardelli A, Saha S, Sager JA, Romans KE, Xin B, Markowitz SD, Lengauer C, Velculescu VE, Kinzler KW, Vogelstein B: PRL-3 expression in metastatic cancers. Clin Cancer Res 2003, 9(15):56075615.

28. Bessette DC, Qiu D, Pallen C): PRL PTPs: mediators and markers of cancer progression. Cancer Metastasis Rev 2008, 27(2):231-252.

29. Zeng Q, Dong JM, Guo K, Li J, Tan HX, Koh V, Pallen CJ, M anser E, Hong W: PRL-3 and PRL-1 promote cell migration, invasion, and metastasis. Cancer Res 2003, 63(11):2716-2722.

30. Gianelly AA, Terner C: Inhibition of cholesterol biosynthesis by dehydroepiandrosterone in lactating mammary gland. Endocrinology 1968, 83(6):1311-1315.

31. Hakkak R, Shaaf S, Jo CH, M acLeod S, Korourian S: Dehydroepiandrosterone intake protects against 7,12-dimethylbenz(a)anthracene-induced mammary tumor development in the obese Zucker rat model. Oncol Rep, 24(2):357-362.

32. M ei JJ, Hursting SD, Perkins SN, Phang JM : p53-independent inhibition of nitric oxide generation by cancer preventive interventions in ex vivo mouse peritoneal macrophages. Cancer Lett 1998, 129(2):191-197.

33. Bosland M C, M cCormick DL, Melamed J, Walden PD, Zeleniuch-Jacquotte A, Lumey LH: Chemoprevention strategies for prostate cancer. Eur J Cancer Prev 2002, 11 Suppl 2:S18-27.

34. Lopez-M arure R, Contreras PG, Dillon JS: Effects of dehydroepiandrosterone on proliferation, migration, and death of breast cancer cells. Eur J Pharmacol, 660(2-3):268-274. 


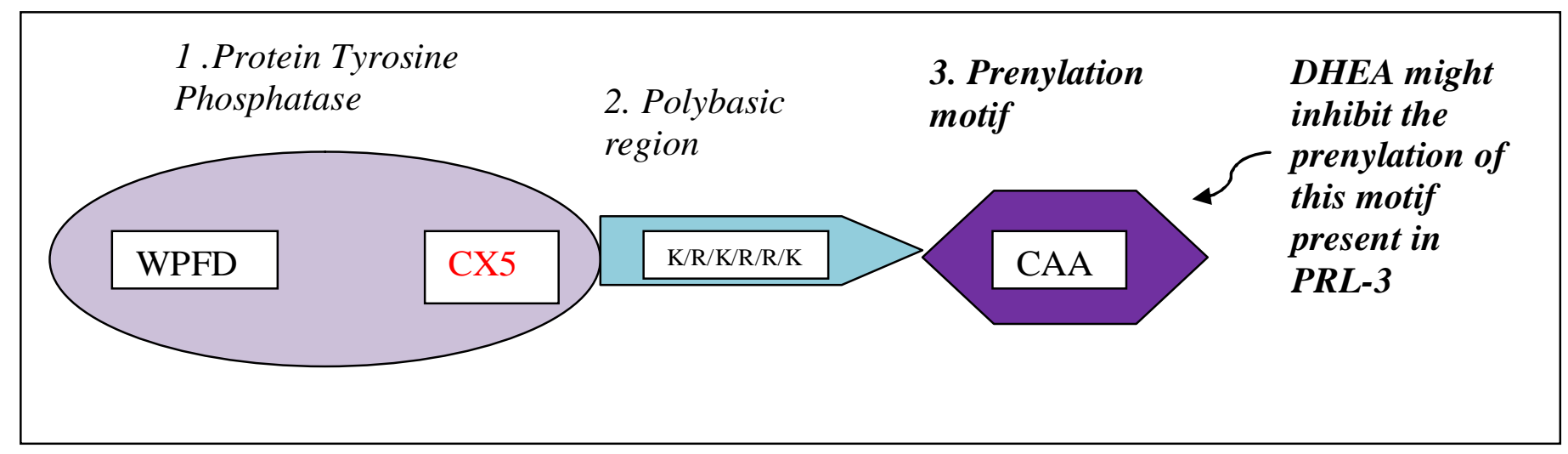

Figure 1. Domain structures in PRL-3 Protein 


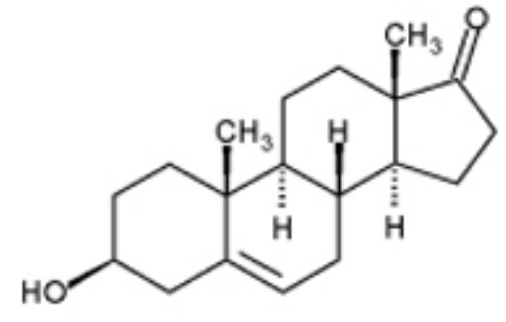

Figure 2. Structure of DHEA 
HMG- CoA

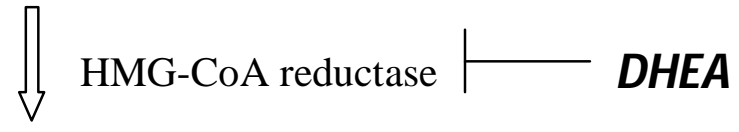

Mevalonate

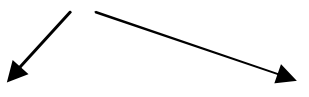

Farnesyl -PP Geranylgeranyl-PP

$\sqrt{ }$

Prenylation of PRL-3

Figure 3. Prenylation pathway 